\title{
Teaching Clinical Ethics in the Formal Curriculum
}

\begin{abstract}
Presenting a full formal curriculum for teaching ethics to health professionals is obviously far beyond the scope of this single chapter. But what we can do here is discuss a range of teaching formats-core lecture course, discussion classes, and observational and participatory activities - that can be used in any field of health care, along with an explanation of how these formats can be used to implement an approach to health care ethics that is centered on the self, informal ethical discourse, and interpretive communities, as presented in Chapters 6 through 8.
\end{abstract}

Keywords Health care - Clinical ethics - Implicit ethical framework Informal ethical discourse - The self · Interpretive community Morality of ordinary practice - Teaching formats - Value of social sciences - Mental health - Cultural competence - Structural competence Patient communication - Informed consent - Shared decision making Counterstories $\cdot$ Reflective practice $\cdot$ Arts-based learning

Since every health care training program will undoubtedly include at least one core, lecture-type course for teaching ethics and other psychosocial issues, we begin this chapter by presenting our suggestions for such a course. We then include suggestions for discussion classes, followed by some remarks on the use of observational/participatory activities such as literature, drama, film, videos, and role playing as methods of moving

(C) The Author(s) 2018

S. Scher and K. Kozlowska, Rethinking Health Care Ethics, https://doi.org/10.1007/978-981-13-0830-7_9 
past "book knowledge" into the more intimate and more lasting knowledge gained through personal experience. In the next chapter (10), we move into the more open structures and methods of teaching available in clinical settings.

Throughout this chapter-which builds upon the general approach to teaching elaborated in Chapter 8-our emphasis is to encourage programs to reorient their ethics teaching away from ethical abstractions (such as ethical principles), to give less emphasis to unsettled, difficult questions of public policy (such as genetic counseling or distribution of scarce resources), and to move toward questions that challenge trainees to extend their existing ethical thinking to the clinical situations encountered in ordinary practice. It is this emphasis on the self and on the ethics of ordinary practice that, we think, will have the most lasting impact on trainees.

Also worth noting is that as trainees develop their own informal ethical thinking - their implicit ethical frameworks - through the processes discussed in this chapter and the next, they do so as entrants to their respective interpretive communities within health care. Progressively immersed in those communities through professional education, trainees acquire, as it were, the distinctive mode of thinking, feeling, and acting that is characteristic of those communities. In the process, they also inescapably acquire a sense of the goals, values, and methods that are embedded in those communities. It is against this background that trainees' informal ethical thinking will develop. ${ }^{1}$

Finally, given our view that the goal in teaching clinical ethics is to nurture trainees' capacities for informal ethical thinking, it is fair to ask about the sort of readings that promote that aim. In the section below, we discuss the central role of the social sciences. But what about the vast literature in bioethics itself? Since we discuss that question in our concluding Chapter 11, we give only the briefest of answers here. In short, the bioethics literature is widely varied in just how much emphasis any particular article gives to formal ethical analysis and ethical principles. We would discourage the use of readings with strong emphases on formal analysis, and encourage the use of readings whose analyses and arguments are closer to the informal language, ethical or otherwise, of everyday discourse. It is the latter sort of readings, which are more closely connected with our standard ways of thinking, feeling, and acting, that will have lasting impact on trainees. 


\section{The Value of the Social Sciences}

Here, as in all of the teaching settings we are discussing in this book, the more one knows about the sociology, history, and anthropology/ psychology of the situations one encounters, the richer will be one's cognitive and emotional responses, and the more adaptive and functional one's subsequent actions. There are numerous dimensions in which such background knowledge enrichens one's experience, but three, in particular, are especially noteworthy.

- The straightforward facts. Does something-bullying, for exampleactually occur with a frequency that renders it a systemic, versus a rare and scattered, problem? A recent Australian study of young doctors (postgraduate years 1 and 2 ) by Anthony Llewellyn and colleagues (2018) found that over half reported having been bullied and that nearly a third of all women reported being sexually harassed. Other studies have found much the same (Carrieri et al. 2018; Barrett and Scott 2018; Flynn 2015; Ivory 2015; Monrouxe et al. 2015; Rees et al. 2015a; Rees et al. 2015b; Scott et al. 2015; Walton 2015).

- Rendering the unfamiliar familiar. Other things equal, a white, male trainee who had attended a prestigious university prior to professional school would have little to no familiarity with the life experience and challenges of an indigenous, Hispanic, or African American woman who had grown up in poverty or near poverty, who is poorly educated, and who has no expectations of ever holding a "good job" or moving past her current life circumstances.

- The possibilities for action. Taking positive, effective action requires understanding and insight. What is the problem? Is it one concerning this particular patient (e.g., providing appropriate care/services to him or her), or is it a larger, systemic issue (dealing with the needs of this group of patients, improving the hospital's system of care for such patients, or even more broadly, achieving change at the local or national political level)? What are the options? Which would be most, or at least decently, effective? These questions all concern the present and future. But understanding these questions will itself depend upon what has happened in the past. How did things get this way? Why wasn't the problem fixed sooner? What forces are still at work and protecting the status quo? ${ }^{2}$ 
As trainees extend their understanding of questions such as the ones above, they are, in effect, extending their selves and become capable of seeing, at a glance, things that were not previously within their perceived worlds. They are, to use our earlier terminology (see Chapter 6), extending their slow thinking, which then, in time, gets entrenched within the self as their fast thinking. And it is typically against a person's established pattern of fast thinking that things occur to them as wrong or concerning or puzzling or challenging. In thus extending the limits of the self and how trainees perceive and understand the world, this new, fast thinking extends, in the process, the range and type of questions that trainees ask and will continue to ask, lifelong-their own, dynamically changing touchstones for learning (as discussed in Chapter 8).

\section{Core Lecture Course}

In deciding what issues to cover in a core lecture course in which ethics is a central, if not exclusive, focus, the challenge is to select topics that will facilitate the transition from preprofessional student to health care trainee, that address potential issues in the here and now (for the trainees themselves), and that will set the stage for lifelong learning and adaptation. In this section, we will focus on three topics that are of particular importance to all fields of health care. Courses in each field of health care, however, should also give close attention to the central issues that are currently affecting, or of concern to, that particular field-to that particular interpretive community.

\section{Mental Health}

An ongoing issue for all trainees-lifelong-concerns their mental health. On this particular topic, a 2018 article in BMJ Open sets the stage for exploring the wide range of factors, both individual and institutional, that potentially compromise the mental health of both trainees and clinicians. As Daniele Carrieri and colleagues note in "Care Under Pressure': A Realist Review of Interventions to Tackle Doctors' Mental Ill-Health and Its Impacts on the Clinical Workforce and Patient Care" (2018, p. 2), the "incidence of mental ill-health (e.g., stress, burnout, depression, drug and alcohol dependence, and suicide)" is increasing "across all groups of health professionals, and in many countries." What makes the article so valuable for teaching purposes is 
that it concisely sets out the various pressures on doctors-which approximate those on all health professionals-and the various sorts of solutions that have been proposed. Key factors identified through the existing literature include the emotionally demanding work, heavy and increasing workload (partly in response to shrinking budgets), long hours, and increasingly regulated professional environment and associated loss of flexibility and autonomy. Unfortunately, what the Carrieri article does not provide is answers. The article is actually just a description of an ambitious study whose overarching questions are described as follows:

1. What are the processes by which mental ill-health in doctors develops and leads to its negative impacts, and where are the gaps that interventions do not address currently?

2. What are the mechanisms, acting at individual, group, profession and organisational levels, by which interventions to reduce doctors' mental ill-health at the different stages are believed to result in their intended outcomes?

3. What are the important contexts which determine whether the different mechanisms [to reduce doctors' mental ill-health] produce the intended outcomes?

4. What changes are needed to existing and/or future interventions to make them more effective? (p. 3)

We have included the full description of the questions here because they set out so thoroughly the range of issues that core courses might choose to address. And although the specific focus of the Carrieri article is on the medical profession, the article and the many issues it raises can be seen as a template for addressing these issues in any field of health care.

\section{Cultural Competence (Extended)}

The easiest place to begin is with the 2005 report by the Association of American Medical Colleges (AAMC), Cultural Competence Education for Medical Students. Though specifically concerned with medical education, its contents apply just as much, with appropriate adjustments, to any other field of health care. The report defines "cultural and linguistic competence [as] a set of congruent behaviors, knowledge, attitudes, and policies that come together in a system, 
organization, or among professionals that enables effective work in cross-cultural situations" (p. 1). This matter of cultural competence was deemed to be of particular importance for U.S. health professionals because of the "ever-increasing diversity of the population of the United States and strong evidence of racial and ethnic disparities in health care" (p. 1).

In terms of substance, the AAMC report defines five domains in which medical students, by the time they graduate, are expected to be competent.

I. Cultural Competence-Rationale, Context, and Definition

II. Key Aspects of Cultural Competence

III. Understanding the Impact of Stereotyping on Medical Decision-Making

IV. Health Disparities and Factors Influencing Health

V. Cross-Cultural Clinical Skills (p. 9)

As is immediately apparent from the full description of these five domains (see Text Box 9.1 and Appendix 9.1), ${ }^{3}$ they are laudable and crucially important. What we suggest, however-and, in part, why we have added the parenthetical extended to the section headingis that these domains of cultural competence should really be used for all patients. That is, we suggest that all health care trainees should be expected to be competent in these domains in relation to all patients, not just those with roots in other cultures.

Text Box 9.1: TACCT [Tool for Assessing Cultural Competence Training] Content Domains

Domain I: Cultural Competence-Rationale, Context, and Definition

A. Definition and understanding of the importance of cultural competence; how cultural issues affect health and health-care quality and cost; and, the consequences of cultural issues

B. Definitions of race, ethnicity, and culture, including the culture of medicine

C. Clinicians' self-assessment, reflection, and self-awareness of own culture, assumptions, stereotypes, biases 


\section{Domain II: Key Aspects of Cultural Competence}

A. Epidemiology of population health

B. Patient/family-centered vs. physician-centered care: emphasis on patients' /families' healing traditions and beliefs [for example, ethno-medical healers] $]^{*}$

C. Institutional cultural issues

D. Information on the history of the patient and his/her community of people

Domain III: Understanding the Impact of Stereotyping on Medical Decision-Making

A. History of stereotyping, including limited access to health care and education

B. Bias, stereotyping, discrimination, and racism

C. Effects of stereotyping on medical decision-making

\section{Domain IV: Health Disparities and Factors Influencing Health}

A. History of health-care design and discrimination

B. Epidemiology of specific health and health-care disparities

C. Factors underlying health and health-care disparities-access, socioeconomic, environment, institutional, racial/ethnic

D. Demographic patterns of health-care disparities, both local and national

E. Collaborating with communities to eliminate disparities-through community experiences

\section{Domain V: Cross-Cultural Clinical Skills}

A. Knowledge, respect, and validation of differing values, cultures, and beliefs, including sexual orientation, gender, age, race, ethnicity, and class

B. Dealing with hostility/discomfort as a result of cultural discord

C. Eliciting a culturally valid social and medical history

D. Communication, interaction, and interviewing skills

E. Understanding language barriers and working with interpreters 
F. Negotiating and problem-solving skills

G. Diagnosis, management, and patient-adherence skills leading to patient compliance

*Pachter, L.M. Ethnomedical (folk) Remedies for Childhood Asthma in a Mainland Puerto Rican Community. Archives of Pediatrics and Adolescent Medicine vol. 149, no. 9, September 1995, pp. 982-988.

From Cultural Competence Education for Medical Students, (C) 2005 American Association of Medical Colleges. Reproduced with permission.

As we see it, it's simply odd that these five domains have been have been singled out for application to cross-cultural situations. The same issues arise for any patient or client, whether from the same or different culture as the care provider. All cultures, including the dominant culture, have an impact on how patients understand health and disease, how they perceive the need for health interventions, and how they perceive health providers and institutions. And even when a health professional believes that he or she has mastered these five domains for his or her own culture, all sorts of questions inescapably arise in providing care or services. Health professionals need to consider who the patient is: man or woman, married or single, gainfully employed or not, sexually active or not, straight or gay (or transgender), young or old, rich or poor. Does the patient have children, and of what age? Is the patient a good historian (re: providing a medical/family/social history)? Is the patient forthcoming or not in the presentation of self and in responding to questions? Does the patient appear to be psychologically settled or, instead, distressed or preoccupied? The questions go on and on.

There is also another set of questions that need to be asked, which concern what Jonathan Metzl and Helena Hansen (2014, p. 127) characterize as structural competence, the capacity to recognize the "forces that influence health outcomes at levels above individual interactions." One of their examples is that the failure of certain patients to exercise reflects not any lack of desire but the lack of opportunity, as when "their neighborhoods have no gyms or sidewalks or parks" (p. 127). 
The controlling idea here is that the factors identified through cultural competence alone are not the sole determinants of how patients present and why. In addition, the

issues defined clinically as symptoms, attitudes, or diseases (e.g., depression, hypertension, obesity, smoking, medication "non-compliance," trauma, psychosis) also represent the downstream implications of a number of upstream decisions about such matters as health care and food delivery systems, zoning laws, urban and rural infrastructures, medicalization, or even about the very definitions of illness and health. (p. 128)

Metzl and Hansen's notion of structural competence is the second way in which we see the notion of cultural competence as needing to be extended. But note: cultural and structural competence are good things not just for cross-cultural patients; they are good things for everybody.

\section{Communication with Patients/Informed Consent/ Shared Decision Making}

All health care programs already devote careful attention to communication with patients, informed consent, and shared decision makingwhich is just as it should be since the relationship between patient and caregiver is the central human phenomenon in health care. What we will do here is simply to comment on how these issues play out in relation to the framework we have presented for thinking about clinical ethics.

Communication with patients. We have noted in earlier chapters that the clinical ethics of health professionals should build upon, and extend, their existing, informal ethical thinking. This foundation in the self is the most efficient and reliable foundation for health professionals to think about the ethical issues that they will confront in their future work. Exactly the same can be said for communicating with patients. That is, at the point that students begin their training in health care, they already have a wide range of existing communication skills. This simple statement has consequences, and a simple example will suffice. Suppose that one is working with social work students to improve their communication skills regarding a particular problem or situation. Consider two questions:

1. How should a social worker discuss this problem with a client?

2. How would you discuss this problem with a client? 
The former question requires trainees to make an intellectual leap into the position of a "social worker." The latter requires no leap at all. That is, trainees have no choice but to start where they are, and as the persons they are. And that's where the education process needs to start, too.

Informed consent. We would guess that more has been written about informed consent than any other topic in the bioethics literature. As in the paragraph above about communicating with patients, we mention here only a few points that connect up with the framework we have presented in earlier chapters.

As background, informed consent, considered as a legal doctrine requiring the mandatory communication of treatment information from health professionals to patients, arose in response to the medical profession's general failure to share such information with patients (see Chapter 3 ). As such, the doctrine was legally imposed upon the various interpretive communities within the field of health care, along with its terminology, concepts, and demands placed on health professionals. When the pristinely simple legal concepts of informed consent-such as legal competence, information about risks and benefits of the different and available treatments, and consequences of non-treatment-encountered the real world of health care, those concepts encountered difficulties. The world proved to be much more complicated, textured, and varied than the one envisioned by the doctrine; among other things, and perhaps most centrally, the supremely rational decision maker envisioned in informed consent, like the supremely rational decision maker of classic economics, simply doesn't exist. The provision of complete information can lead, among other things, to informational or emotional overload (Bester et al. 2016). And as Christine Grady notes in her (2015) New England Journal of Medicine article, "Enduring and Emerging Challenges of Informed Consent," the fundamental legal requirements of the doctrine remain matters of ongoing debate, including

the scope and level of detail provided and the methods of disclosure, whether and how to assess comprehension, what constitutes necessary and sufficient understanding for valid consent, approaches to assessing persons' capacity to consent and steps taken when they lack that capacity, how to know when choices are sufficiently voluntary, and issues concerning the documentation of consent. (p. 856) 
What makes these problems even more difficult for clinicians is that the legal doctrine actually calls, of necessity, for legal answers. That is, insofar as clinicians have questions about what is or is not required, they can make good guesses, but they simply don't have the capacity to arrive at legally authoritative answers. To us, it seems that clinicians have thereby been put in the remarkably odd position of being legally required to do something whose very standards and rules, except in central cases, are poorly defined.

What, then, is a clinician to do? Our answer has three interconnected parts: (1) Inescapably, since no health professional constantly has access to a lawyer, health professionals need to rely on their own best judgment in determining whether particular patients have the capacity to make decisions about their care and whether they understand their health situations and information provided about the available options, including a refusal of treatment. (2) The capacity of particular health professionals to make such judgments about their patients can be maximized by their learning, beginning with their formal courses as trainees, about the limits and problems of the informed consent doctrine (see Grady quote above), which will then help them to recognize these problems in practice and will put caregivers on notice that they need to pay special attention to those elements of the decision/treatment process. (3) The communication process that best promotes (1) and (2) is shared decision making (see following subsection) as complemented by training in communication with patients (see preceding subsection and Chapter 10).

Shared decision making. As we noted in discussing informed consent, the more that health professionals know about the limits and problems of informed consent-in this context, the limits and problems of patients in deciding what treatment they want-the better prepared clinicians will be to identify and address such problems in providing care to their patients. But the differences between informed consent and shared decision making are dramatic. Informed consent arose out of an effort to protect patients from the failures of health professionals, and it defines what is, legally speaking, the legally minimum standard for discussing health care options with patients (or their families or substitute decision makers). Such a standard is, for those working in the various interpretive communities of health care, both externally imposed and, as discussed above, unable to capture the complexities of clinical practice. By contrast, the process of shared decision making represents an opportunity. It connects up directly, at least in theory, ${ }^{4}$ with the central aim of health 
professionals to provide the best, most responsive care to their patients; this aim is embedded in the very organization of health professionals' respective interpretive communities; and the process highlights and builds upon the very achievements of those communities. In short, shared decision making is a process through which clinicians and patients come to agree on the best care for that particular patient. And because modern health care has so many options available and also has the capacity to describe the options and their likely and possible consequences, shared decision making is actually a product of the health professions' strengths, not their failures. Importantly, too, since numerous options are typically available for any particular health care situation, the decision process cannot reach closure by consulting the health care "facts." On that basis alone, no single best option can be objectively determined. What does make something the best option is that, when provided the needed information and the opportunity to discuss the available options with the clinician, the patient has chosen that particular option.

The implication of the above is that shared decision making provides the opportunity for health professionals to use their communications skills effectively to assist patients in making their health care decisions. Just what information to provide, how to provide it, how to discuss it, and such matters are all things that health professionals need to decide. It challenges them to use every bit of their communication know-how to frame the decision process and move the patient through it. In this respect, teaching health professionals about shared decision making is a direct extension of any other work that they do to improve their communication with patients (as discussed in the first of these three subsections on communication).

\section{Discussion Classes}

Regularly scheduled discussion classes could take place in conjunction with lecture courses, as part of freestanding discussion courses, as workshops, or potentially even as portions of clinical rotations (for this last type, see "Formal Clinical Modules" in Chapter 10). Depending upon the flexibility of the discussion classes, the specific choice of discussion topics might be set in advance by the course syllabus, at one extreme, or could be chosen by the trainees themselves on an ad hoc basis via the touchstones for learning discussed in Chapter 8, at the other. For reasons also discussed in Chapter 8, ideal group sizes would be from five to fifteen, though that depends upon the availability of resources of various types. 
But our concern here is on process and materials, not course structure as such. Our recommendation would be for discussion classes to focus on clinical and other work-related situations, to use literary, dramatic, and video/film materials whenever available and relevant (see Sect. "Observational and Participatory Activities," below), and to supplement both with appropriate readings in sociology, history, and anthropology/ psychology. The closer that the discussion materials can get to the actual, current lived experience of trainees, the better. The use of materials that lead to exploration and reflection, rather than conflict, is to be preferred. No matter what the materials, the goal is, of course, to extend and enrich trainees' informal ethical thinking.

\section{Selecting Topics for Discussion}

In any discussion course in which the touchstones for learning, with their very personal orientation, are considered a primary means of identifying issues for discussion - and also for maintaining discussion-a potential threshold matter is getting trainees to "open up." To address this problem and also to reveal, at the outset of any discussion course, both the commonality of various problems and the range of possible topics for discussion, an excellent place to start is with Grace Under Pressure (Williams and Dwyer 2017). This 90-minute dramatic presentation, available in script form, draws from actual interviews with health professionals (doctors and nurses, at various stages of their careers) and gives central attention to professional training. In the course of the presentation, the characters discuss matters such as bullying by senior professionals, overly long working hours (including dangers to patients and to oneself, as in driving home after long or night shifts), sexual harassment, the need to care for oneself, and mental health and suicidal ideation among trainees, among various other topics. This brief presentation, whether read in segments or in its entirety, is a remarkably efficient way of legitimating these sorts of topics and creating a space that is safe for discussion.

In other discussion courses the topics for discussion will be largely determined in advance. The following clinical situation, drawn from the early years of the AIDS epidemic, is an example of what can be used to generate discussion-in this instance to explore the limits of health professionals' obligations to patients: 
A mother, a widow, is taking care of her son, who is dying of AIDS, at home. Hospice care is available, but the mother is unwilling for her son to be moved there from the family's apartment, where they have lived ever since moving to the United States from Haiti twenty years earlier. She wants the son to spend his last weeks in the room he lived in as a child, and she requests that the available health care services-from his doctor, a nurse, and a social worker-be provided at home. The health professionals balk at providing the services there when hospice care is available, and they also note that the mother has been unable to comply with general precautions concerning bodily fluids. The bedroom and bed are filthy, and the rest of the apartment is presumably contaminated. In an agonizing decision, the health professionals decide that they are unable to provide further care to the patient in that location (though they also noted [among themselves] that they had no overarching theory of where to draw the line between what they should or shouldn't do in meeting the personal preferences and needs of individual patients; the line they drew here was ad hoc). The mother, on being informed of the team's decision, calls them "selfish brutes" who "obviously don't give a damn for patients, just themselves." Several weeks later the patient dies at home, with no further medical/nursing/social interventions.

The above situation presents many questions about the limits of professional obligations and the extent to which health professionals should make adjustments for the needs of individual patients. A separate question is whether some middle ground, such as an effort to provide training on issues of safety or to provide counseling to address issues of loss and grief, might have been pursued before any final decision was made.

\section{Stories and Counterstories}

But once an event or phenomenon or situation has been identified as the subject for a discussion, what happens then? In addition to the standard ways of encouraging and maintaining discussion-including the use of hyphotheticals, the touchstones for learning (e.g., "Why does that bother/surprise/please you?"), and probing and open-ended questions-we strongly support the ongoing work in the field now known as narrative ethics. ${ }^{5}$ There can be no doubt that stories, or narratives, are valuable both in teaching and in understanding the complexities of clinical health care. What we want to do here, however, is explore the use of counterstories as a variation on that particular theme-and, in particular, as an especially efficient and effective way of helping trainees 
(and others) to perceive and come to understand clinical situations from diverse, even unfamiliar perspectives.

In his classic, 1989 article, "Storytelling for Oppositionists and Others: A Plea for Narrative," Richard Delgado set out the notion of counterstories, which are stories, or narratives, by or about members of outgroupsgroups of persons/outsiders who have been "suppressed, devalued, and abnormalized" (p. 2412). The example that Delgado makes the centerpiece of his account concerns a law school's decision not to hire a particular African American to fill an advertised opening on its faculty. In explaining the decision, the members of the tenured faculty, all white, provide

an account that justifies the world as it is. It emphasizes the school's benevolent motivation ("look how hard we're trying") and good faith. It stresses stability and the avoidance of risks. It measures the black candidate through the prism of preexisting, well-agreed-upon criteria of conventional scholarship and teaching. (p. 2421, footnote omitted)

But the various alternative counterstories-by the candidate, his lawyer (in a court submission), a radical student, and an anonymous leaflet-all challenge the status quo, though they do so in different ways, with different emotional tones and with ultimately different chances of swaying the opinions of those who had initially accepted the standard story.

As Delgado notes, counterstories "invite the listener to suspend judgment, listen for the story's point, and test it against his or her own version of reality" (p. 2440). They can

challenge the received wisdom ... [and] can open new windows into reality, showing us that there are possibilities for life other than the ones we live. They enrich imagination and teach that by combining elements from the story and current reality, we may construct a new world richer than either alone. Counterstories can quicken and engage conscience. Their graphic quality can stir imagination in ways in which more conventional discourse cannot. (pp. 2414-2415, footnote omitted)

So understood, many of the situations identified through the touchstones for learning will potentially be subject to different interpretations, different narratives, with the trainee being the outsider who sees the status quo as disturbing or concerning or surprising. Grace Under Pressure itself presents many such situations from the trainees' perspective (Williams and Dwyer 
2017). In other situations - which would be more common in relation to topics taken up as part of a predetermined syllabus-the outsider is more likely to be someone other than the trainee or the health professional involved (as in the AIDS situation above). The teaching challenge, in those situations, is to lead trainees to see (and potentially, through literature, drama, or video/film, to experience) the situation through an outsider's eyes and even to construct a story, or narrative, that captures that perspective. As with Delgado's case of the African American who was rejected by an all-white faculty, there is no single, unique counterstory; for any particular situation, different counterstories capture different perspectives and reflect different interests and goals. This diversity is exactly why they can be so useful to trainees in expanding their intellectual perspectives and increasing their emotional resources.

To return to the vignette above concerning the AIDS patient who died at home, the basic story from the perspective of the health care team is that they were unwilling to put their own lives at risk through avoidable exposure to the AIDS virus in a contaminated home environment. But consider two counterstories:

- From a critic of the U.S. health care system. The health care team did exactly what it has been trained to do: treat the disease, not the person. It is obvious that, had the team seen the situation more broadly, the mother was determined, no matter what, to see her son die at home. This baseline problem could have been identified and addressed much earlier, before the problem of contamination got out of control. The social worker, who was meeting with the mother to support her in her grief (and maybe to negotiate things financially), could have brought this growing problem to the team's attention and also started working with the mother, aiming either to secure her understanding that hospice care could be an acceptable option (allowing her regular, intimate access to her son) or that, if the son was to stay at home, she would need to learn and follow sanitary precautions for home care of AIDS patients. What we can't know from the vignette is whether the social worker had explored the patient's living situation, whether she was effectively blinded by having medicalized the situation (seeing only the medical problems), or whether she and possibly also the nurse had found themselves powerless to protest the treating doctor's narrow view of the situation and the available options. 
- From a community organizer/political activist. The story presented is one of racism. The presumably white health care team made a decision regarding a Haitian patient (and his mother) that they would never have made if the patient and mother had been white. They conceived the situation as "us versus them," comfortably setting the cost of proceeding with home care as so high that they needed to exit the situation. Their loyalty to this patient and his mother was too thin to justify the risk or to motivate the team to identify possible alternatives (see A. O. Hirschman's Exit, Voice, and Loyalty [1970]).

These two counterstories put the initial vignette in different, much more critical lights. What's noteworthy, too, is that seeing these criticisms as stories rather than simply as summary criticisms - the first as reflecting a narrow, medicalized view of the situation and the second as demonstrating its implicit racism-makes the criticisms much more powerful and personal. Stories connect up with the whole person, whereas the bare criticisms connect up mainly with the intellect, making it much easier to rationalize and disregard what happened and why.

\section{Observational and Participatory Activities}

The literature on the use of observational and participatory activities in health care education is already extensive, of course, but our particular focus here is on using these media not only to connect up learning with the self but to do so in a way that enhances or extends what might be called one's ethical self or ethical imagination. In this context, it's helpful to draw again on the notion of counterstories.

The central idea behind counterstories is that actual or imagined factual situations that include a variety of different human perspectives provide rich material for thinking about, and learning about what it is to inhabit, the world from those different perspectives. The potential for learning is even further enhanced when the situations are, as it were, given human form, as in live dramas and videos or role playing. Even if the factual situation is "closed" - that is, with the events already over and with no further decisions to be made-the cross-currents of the stories, embodied in human form, invite observers to occupy various positions both intellectually and emotionally, and to construct a story from that perspective. Similarly, as in role playing through a situation that presents 
human conflicts or difficulties of one kind or another, participants (and also, indirectly, observers) find themselves living a story or counterstory, and constructing a view of the world, and experiencing it, from that perspective.

To return briefly to our example of Grace Under Pressure, the counterstories take human form as the relatively powerless, striving, vulnerable trainees discuss how they have been sexually harassed, bullied by their seniors, or unable to protest overly long hours (Williams and Dwyer 2017). At the University of Sydney, a number of these counterstories from Grace Under Pressure have been re-filmed close-up, for use in teaching (personal communication, Paul Dwyer and Louise Nash). At many other universities, health care training programs have collaborated with members of the institutions' art faculties to develop drama workshops (de la Croix et al. 2011). Another potentially valuable format is forum theater, "an interactive approach for exploring a difficult situation and possible solutions by having actors perform a short scene, and then inviting members of the audience to come forward with different options for addressing the problematic situation" (Brett-MacLean et al. 2012, p. 1; Booton and Dwyer 2006; Ivory et al. 2016; Kumagai et al. 2007; Brown and Gillespie 1997). ${ }^{6}$ During a replay, "audience members . . . are invited to stop the performance and suggest, or act out, an idea for how one of the characters could have acted differently to effect a positive change that would have resulted in a better outcome" (BrettMacLean et al. 2012, p. 1). As the original scenario and suggested alternative actions are discussed, what emerge, in effect, are a series of stories and counterstories-for example, as those in power change their behavior or those with less power take less subservient, more self-expressing stances.

Some health care training programs have even developed formal courses in collaboration with their universities' drama departments or programs (Willson 2006; Willson and Jaye 2017). In the resulting teaching modules, trainees interact with actors or with each other to develop communication skills, deal with conflict, interpret body language, and experience the problems, complications, and challenges characteristic of each particular field of health care. These opportunities also provide some form of lived experience of occupying perspectives other than one's own and, in the process, of generating and experiencing a range 
of stories and counterstories (Scott et al. 2017; de la Croix et al. 2011; Jeffrey et al. 2012; Reilly et al. 2012; Bell et al. 2014; Hammer et al. 2011; Willson 2006; Willson and Jaye 2017).

This formal coursework-lecture courses, class discussions, and observational/participatory activities_serves as a bridge between trainees' preprofessional, informal ethical frameworks and the challenges of their clinical work. Most importantly, through the touchstones for learning and trainees' complementary learning in sociology, history, and anthropology/psychology, trainees should be better able-in their own, informal ethical thinking-to identify various problems and deficiencies in their professional environments (i.e., their respective interpretive communities), articulate what is wrong, think about how it got that way, and formulate potential means of improving the situation. They should feel more confident in raising their ethical and other concerns with their peers and their seniors, and should come to appreciate the value of discussion, both for bringing out various dimensions of the problems encountered and for reaching some sort of consensus, a way of going forward. They should, in short, be well prepared, at least on a human level, for the clinic.

\section{Notes}

1. See Sects. "Interpretive Communities" and "Health Care as Overlapping Interpretive Communities" in Chapter 7.

2. These questions would be considered to fall within structural competence (Metzl and Hansen 2014), as discussed later in this chapter.

3. Appendix 9.1 provides a sampling from different models of cross-cultural communication. These descriptions of the different models, reproduced from the same (2005) AAMC report as the material in Text Box 9.1, provide an easily accessible overview of how to facilitate communication with cross-cultural patients (and, indeed, with all patients).

The online resources on cross-cultural communication in health care are vast. Good places to start are with U.S. Health Resources and Services Administration's Culture, Language and Health Literacy Web page, and Georgetown University's National Center for Cultural Competence.

4. It would be wrong to infer that shared decision making always leads to optimal choices and the best outcomes. The title of the review "Shared Decision Making and Improving Health Care: The Answer Is Not In" (2017), by Victor Montori, Marleen Kunneman, and Juan P. Brito, speaks for itself. Shared decision making remains, in this context, a work in progress. But it is a work that is progressing in the right direction, that incorporates the respective perspectives 
of both patients and health professionals into decision making, and that unequivocally recognizes and respects the stake of patients in their own health care.

5. See, for example, Howard Brody, Stories of Sickness (1987); Rita Charon and Martha Montello, eds., Stories Matter: The Role of Narrative in Medical Ethics (2002); Rita Charon, Narrative Medicine: Honoring the Stories of Illness (2006); and Martha Montello, ed., "Special Report: Narrative Ethics: The Role of Stories in Bioethics" (2014).

6. It is also possible to use student actors to perform the scene, thereby both saving money and potentially increasing the educational impact.

\section{Appendix 9.1: Models of Effective Cross-Cultural Communication and Negotiation}

\begin{tabular}{l}
\hline Models \\
BATHE \\
Background (What is going on in your li \\
Affect (How do you feel about what is \\
going on?) \\
Trouble (What troubles you most?) \\
Handling (How are you handling that?) \\
Empathy (This must be very difficult for \\
you.)
\end{tabular}

\section{BELIEF}

Beliefs about health (What caused your illness/problem?)

Explanation (Why did it happen at this time?)

Learn (Help me to understand your belief/ opinion.)

Impact (How is this illness/problem impacting your life?)

Empathy (This must be very difficult for you.)

Feelings (How are you feeling about it?)

\section{Eliciting Patient Information and} Negotiating

Identify core cross-cultural issues

Explore the meaning of the illness

Determine the social context

Engage in negotiation

\section{Sources}

Stuart, M. R., Leibermann, J. R. (1993).

The fifteen-minute hour: Applied psychotherapy for the primary care physician. New York: Praeger

Dobbie, A. E., Medrano, M., Tysinger, J., Olney, C. (2003). The BELIEF instrument: A preclinical teaching tool to elicit patients' health beliefs. Family Medicine, 35, 316-319

Carrillo, J. E., Green, A. R., \& Betancourt, J. R. (1999). Cross-cultural primary care: a patient-based approach. Annals of Internal Medicine, 130(10), 829-834 


Models
ESFT model for communication and
compliance
Explanatory model
Social risk for noncompliance
Fears and concerns about the medication
Therapeutic contracting and playback
ETHNIC
Explanation (How do you explain your
illness?)
Treatment (What treatment have you tried?)
Healers (Have you sought any advice from
folkhealers?)
Negotiate (mutually acceptable options)
Intervention (agreed on)
Collaboration (with patient, family, and
healers)

Kleinman's questions

What do you think has caused your problem?

Why do you think it started when it did?

What do you think your sickness does to you?

How severe is your sickness? Will it have a short or long course?

What kind of treatment do you think you should receive?

What are the most important results you hope to receive from this treatment?

What are the chief problems your sickness has caused for you?

What do you fear most about your sickness?

\section{LEARN}

Listen with sympathy and understanding to the patient's perception of the problem

Explain your perceptions of the problem

Acknowledge and discuss the differences and similarities

Recommend treatment

Negotiate treatment

\section{Sources}

Betancourt, J. R., Carrillo, J. E., \& Green, A. R. (1999). Hypertension in multicultural and minority populations: Linking communication to compliance. Current Hypertension Reports, 1(6), 482-488

Levin, S. J., Like, R. C., Gottlieb, J. E. (2000). ETHNIC: A framework for culturally competent ethical practice. Patient Care, 34(9), 188-189

Kleinman, A., Eisenberg, L., Good, B. (1978). Culture, illness, and care:

Clinical lessons from anthropologic and cross-cultural research. Annals of Internal Medicine, 88, 251-258

Berlin, E. A., Fowkes, W. C. (1983).

A teaching framework for cross-cultural health care. The Western Journal of Medicine, 139, 934-938 


\begin{tabular}{ll}
\hline Models & Sources \\
\hline $\begin{array}{l}\text { Model for Cultural Competency in } \\
\text { Health Care }\end{array}$ & $\begin{array}{c}\text { Flores, G. (2000). Culture and the } \\
\text { patient-physician relationship: Achieving } \\
\text { Normative cultural values } \\
\text { Language issues }\end{array}$ \\
$\begin{array}{l}\text { Foltural competency in health care. } \\
\text { Patient/parent beliefs }\end{array}$ & \\
$\begin{array}{l}\text { Provider practices } \\
\text { "Review of Systems" domains of the }\end{array}$ & Green, A. R., Betancourt, J. R., \& Carrillo, \\
Social Context & J. E. (2002). Integrating social factors \\
Social stressors and support network & into cross-cultural medical education. \\
Change of environment & Academic Medicine, 77(3), 193-197 \\
Life control & \\
Literacy &
\end{tabular}

From Cultural Competence Education for Medical Students, (C) 2005 American Association of Medical Colleges. Reproduced with permission.

\section{REFERENCES}

Association of American Medical Colleges. (2005). Cultural competence education for medical students. https://www.aamc.org/download/54338/data/.

Barrett, J., \& Scott, K. M. (2018). Acknowledging medical students' reports of intimidation and humiliation by their teachers in hospitals. Journal of Paediatrics and Child Health, 54(1), 69-73. https://doi.org/10.1111/jpc.13656.

Bell, S. K., Pascucci, R., Fancy, K., Coleman, K., Zurakowski, D., \& Meyer, E. C. (2014). The educational value of improvisational actors to teach communication and relational skills: Perspectives of interprofessional learners, faculty, and actors. Patient Education and Counseling, 96(3), 381-388. https://doi. org/10.1016/j.pec.2014.07.001.

Bester, J., Cole, C. M., \& Kodish, E. (2016). The limits of informed consent for an overwhelmed patient: Clinicians' role in protecting patients and preventing overwhelm. AMA Journal of Ethics, 18(9), 869-886. https://doi. org/10.1001/journalofethics.2016.18.9.peer2-1609.

Booton, J., \& Dwyer, P. (2006). "Legal Theatre": A theatre-based approach to community legal education [Report for the Law and Justice Foundation of New South Wales]. Sydney: LJFNSW. http://www.lawfoundation.net.au/ljf/ app/\&id=8D19068DB99E3D7CCA25720C000AAC3F\#may.

Brett-MacLean, P., Yiu, V., \& Farooq, A. (2012). Exploring professionalism in undergraduate medical and dental education through forum theatre. Journal for Learning through the Arts, 8(1). https://escholarship.org/uc/ item/50p52s33s. 
Brody, H. (1987). Stories of sickness. New Haven, CT: Yale.

Brown, K. H., \& Gillespie, D. (1997). We become brave by doing brave acts: Teaching moral courage through the theatre of the oppressed. Literature and Medicine, 16(1), 108-120.

Carrieri, D., Briscoe, S., Jackson, M., Mattick, K., Papoutsi, C., Pearson, M., et al. (2018). 'Care under pressure': A realist review of interventions to tackle doctors' mental ill-health and its impacts on the clinical workforce and patient care. British Medical Journal Open, 8(2), e021273. https://doi. org/10.1136/bmjopen-2017-021273.

Charon, R. (2006). Narrative medicine: Honoring the stories of illness. New York: Oxford University Press.

Charon, R., \& Montello, M. (2002). Stories matter: The role of narrative in medical ethics. New York: Routledge.

de la Croix, A., Rose, C., Wildig, E., \& Willson, S. (2011). Arts-based learning in medical education: The students' perspective. Medical Education, 45(11), 1090-1100. https://doi.org/10.1111/j.1365-2923.2011.04060.x.

Delgado, R. (1989). Storytelling for oppositionists and others: A plea for narrative. Michigan Law Review, 87(8), 2411-2441. https://doi. org/10.2307/1289308.

Flynn, J. M. (2015). Not so innocent by standers. Medical Journal of Australia, 203(4), 163-164.

Georgetown University's National Center for Cultural Competence. https:// nccc.georgetown.edu.

Grady, C. (2015). Enduring and emerging challenges of informed consent. New England Journal of Medicine, 372(22), 2172. https://doi.org/10.1056/ NEJMc1503813.

Hammer, R. R., Rian, J. D., Gregory, J. K., Bostwick, J. M., Barrett Birk, C., Chalfant, L., et al. (2011). Telling the patient's story: Using theatre training to improve case presentation skills. Journal of Medical Humanities, 37(1), 18-22. https://doi.org/10.1136/jmh.2010.006429.

Hirschman, A. O. (1970). Exit, voice, and loyalty: Responses to decline in firms, organizations, and states. Cambridge, MA: Harvard University Press.

Ivory, K. D. (2015). Listen, hear, act: Challenging medicine's culture of bad behaviour. Medical Journal of Australia, 202(11), 563-564.

Ivory, K. D., Dwyer, P., \& Luscombe, G. (2016). Reactions to diversity: Using theater to teach medical students about cultural diversity. Journal of Medical Education and Curricular Development, 3. https://doi.org/10.4137/jmecd. s37986.

Jeffrey, E. J., Goddard, J., \& Jeffrey, D. (2012). Performance and palliative care: A drama module for medical students. Journal of Medical Humanities, 38(2), 110-114. https://doi.org/10.1136/medhum-2012-010203. 
Kumagai, A. K., White, C. B., Ross, P. T., Purkiss, J. A., O’Neal, C. M., \& Steiger, J. A. (2007). Use of interactive theater for faculty development in multicultural medical education. Medical Teacher, 29(4), 335-340.

Llewellyn, A., Karageorge, A., Nash, L., Li, W., \& Neuen, D. (2018). Bullying and sexual harassment of junior doctors in New South Wales, Australia: Rate and reporting outcomes. Australian Health Review [Epub ahead of print].

Metzl, J. M., \& Hansen, H. (2014). Structural competency: Theorizing a new medical engagement with stigma and inequality. Social Science and Medicine, 103, 126-133. https://doi.org/10.1016/j.socscimed.2013.06.032.

Monrouxe, L. V., Rees, C. E., Dennis, I., \& Wells, S. E. (2015). Professionalism dilemmas, moral distress and the healthcare student: Insights from two online UK-wide questionnaire studies. BMJ Open, 5(5), e007518. https://doi. org/10.1136/bmjopen-2014-007518.

Montello, M., ed. (2014). Special report: Narrative ethics: The role of stories in bioethics. Hastings Center Report, 44(1 Suppl.), S1. https://doi. org/10.1002/hast.260.

Montori, V. M., Kunneman M., \& Brito, J. P. (2017). Shared decision making and improving health care: The answer is not in. Journal of the American Medical Association, 318(7), 617-618.

Rees, C. E., Monrouxe, L. V., \& McDonald, L. A. (2015a). 'My mentor kicked a dying woman's bed . . ' Analysing UK nursing students' 'most memorable' professionalism dilemmas. Journal of Advanced Nursing, 7l(1), 169-180. https://doi.org/10.1111/jan.12457.

Rees, C. E., Monrouxe, L. V., Ternan, E., \& Endacott, R. (2015b). Workplace abuse narratives from dentistry, nursing, pharmacy and physiotherapy students: A multi-school qualitative study. European Journal of Dental Education, 19(2), 95-106. https://doi.org/10.1111/eje.12109.

Reilly, J. M., Trial, J., \& Piver, D. E. (2012). Using theater to increase empathy training in medical students. Journal for Learning through the Arts, $8(1)$. https://files.eric.ed.gov/fulltext/EJ985626.pdf.

Scott, K. M., Berlec, S., Nash, L., Hooker, C., Dwyer, P., Macneill, P., et al. (2017). Grace under pressure: A drama-based approach to tackling mistreatment of medical students. Journal of Medical Humanities, 43(1), 68-70. https://doi.org/10.1136/medhum-2016-011031.

Scott, K. M., Caldwell, P. H., Barnes, E. H., \& Barrett, J. (2015). "Teaching by humiliation" and mistreatment of medical students in clinical rotations: A pilot study. Medical Journal of Australia, 203(4), 185e.1-6. https://www. mja.com.au/journal/2015/203/4/teaching-humiliation-and-mistreatment-medical-students-clinical-rotations-pilot.

U.S. Health Resources and Services Administration. Culture, language and health literacy. https://www.hrsa.gov/cultural-competence/. 
Walton, M. M. (2015). Sexual equality, discrimination and harassment in medicine: It's time to act. Medical Journal of Australia, 203(4), 167-169.

Williams, D., \& Dwyer, P. (2017). Grace under pressure. Presented by the Seymour centre for the big anxiety festival. Strawberry Hills: Currency Press.

Willson, S. (2006). What can the arts bring to medical training? Medicine and creativity. Lancet, 368(Suppl. 1), S15-S16.

Willson, S., \& Jaye, P. (2017). The art of medicine. Arts-based learning for a circle of care. Lancet, 390, 642-643.

Open Access This chapter is licensed under the terms of the Creative Commons Attribution-NonCommercial-NoDerivatives 4.0 International License (http:// creativecommons.org/licenses/by-nc-nd/4.0/), which permits any noncommercial use, sharing, distribution and reproduction in any medium or format, as long as you give appropriate credit to the original author(s) and the source, provide a link to the Creative Commons license and indicate if you modified the licensed material. You do not have permission under this license to share adapted material derived from this chapter or parts of it.

The images or other third party material in this chapter are included in the chapter's Creative Commons license, unless indicated otherwise in a credit line to the material. If material is not included in the chapter's Creative Commons license and your intended use is not permitted by statutory regulation or exceeds the permitted use, you will need to obtain permission directly from the copyright holder.

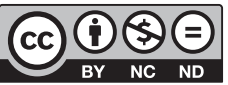

